\title{
Polychlorinated Naphthalenes and Polychlorinated Biphenyls in Benthic Organisms of a Great Lakes Food Chain
}

\author{
N. Hanari, ${ }^{1}$ K. Kannan, ${ }^{2}$ Y. Horii, ${ }^{1}$ S. Taniyasu, ${ }^{1}$ N. Yamashita, ${ }^{1}$ D. J. Jude, ${ }^{3}$ M. B. Berg ${ }^{4}$ \\ 1 National Institute of Advanced Industrial Science and Technology, 16-1 Onogawa, Tsukuba, wapan \\ ${ }^{2}$ Wadsworth Center and Department of Environmental Health and Toxicology, State University of New York at Albany, Albany, NY 12201-0509, \\ ${ }^{3}$ School of Natural Resources and the Environment, University of Michigan, 501 East University, Ánn Arbor, MI 48109, USA \\ ${ }^{4}$ Department of Biology, Loyola University Chicago, 6525 North Sheridan Road, Chicago, $\amalg$ 60626, USA
}

Received: 6 June 2003/Accepted: 5 August 2003

\begin{abstract}
Invasion of zebra mussels, Dreissena polymorpha, and round gobies, Neogobius melanostomus, into the Great Lakes has altered the food web structure and thereby the pathways of toxic contaminants such as polychlorinated biphenyls (PCBs) and polychlorinated naphthalenes (PCNs). In this study, concentrations of PCNs and PCBs were measured in organisms of a Great Lakes benthic food chain encompassing zebra mussels. PCNs were found in all of the benthic organisms, including phytoplankton, algae, amphipods, zebra mussels, round goby, and smallmouth bass, Micropterus dolomieui. Concentrations of PCNs were greater in samples collected from the Raisin River than in samples from the St. Clair River. Biomagnification factors (BMF) for tetra- through octa-CN congeners in going from algae to zebra mussels from the St. Clair River ranged from 3 to 10 . No major biomagnification of PCNs was found in round gobies, when concentrations were related to those in their prey species, zebra mussels. The biomagnification potential of PCNs appears to be similar to that of PCBs in the benthic food chain investigated in this study, despite the fact that PCNs may be metabolized by organisms higher in the food chain. Among several congeners, the BMFs of PCN congeners $35,42,43 / 45,52 / 60,58$, and $66 / 67$ were highest in round gobies. PCNs accounted for $1-22 \%$ of the total TEQs (toxic equivalents) of PCBs and PCNs in benthic organisms analyzed in this study. PCB congener 126 was the major contributor to TEQs, accounting for $72-99 \%$ of the PCB-TEQs in the food chain organisms analyzed.
\end{abstract}

Polychlorinated naphthalenes (PCNs), like polychlorinated biphenyls (PCBs), are widespread, persistent environmental pollutants. PCNs have been detected in samples of air, water, and

Correspondence to: K. Kannan, Wadsworth Center, New York State Department of Health, Empire State Plaza, P.O. Box 509, Albany, NY 12201-0509, USA; email: kkannan@wadsworth.org biota collected from the remote oceans, including the Arctic Ocean (Harner et al. 1998; Helm et al. 2002; Corsolini et al. 2002). Although PCNs are ubiquitous pollutants, reports of their accumulation in the food chain are scarce, compared with PCBs. Biomagnification of PCNs in pelagic and benthic food chains of the Baltic Sea has been documented (Falandysz et al. 1996; Falandysz 1998; Lundgren et al. 2002). These studies have shown that, among 75 PCN congeners, only a few biomagnify in the food chain (Falandysz et al. 1997; Lundgren et al. 2002). Hexachloronaphthalene congeners 66/67, 69, and $71 / 72$ were the most bioaccumulative in four-horned sculpins, Myoxocephalus quadricornis, when concentrations were compared with those in their prey species, amphipods (Lundgren et al. 2002). In sea eagles and cormorants, chloronaphthalene (CN) congeners $42,52 / 60,54,58,61,64 / 68,66 / 67,69$, and $71 / 72$ were the most bioaccumulative ones (Falandysz et al. 1997). Moreover, patterns of PCN congeners retained in biota, particularly those at the lower trophic levels in the food chain, vary considerably, depending on the source of exposure $(\mathrm{Fa}$ landysz et al. 1996; Järnberg et al. 1997; Kannan et al. 1998, 2000). Therefore, biomagnification of PCN congeners is expected to vary depending on location and species. Differences in $\mathrm{CN}$ congener composition in benthic organisms, coupled with congener-specific biomagnification, necessitate a site-specific approach to the evaluation of food chain transfer of PCNs. While earlier studies have examined trophic transfer of PCNs in the Baltic Sea (Falandysz et al. 1997; Lundgren et al. 2002), no information on the accumulation of PCNs in organisms in a Great Lakes food chain has been reported prior to this study. In this study, freshwater aquatic organisms were collected from the International Joint Commission (IJC) designated Areas of Concern (AOC) including the Raisin River (a tributary of Lake Erie), the Saginaw River (a tributary to Lake Huron), and the St. Clair River, Michigan, USA. The major objective of this study was to examine the concentrations and transfer of PCNs and PCBs in the zebra mussels, Dreissena polymorpha-round gobies, Neogobius melanostomus-smallmouth bass, Micropterus dolomieui, food chain.

This study is of particular significance because the invasion 
of the Great Lakes by zebra mussels in the late 1980s and round gobies in the early 1990s (Jude et al. 1992) represents a new mechanism for the mobilization of toxic organic contaminants, such as PCNs and PCBs, from benthic organisms to higher trophic levels. Zebra mussels are filter feeders and feed primarily on algae, plankton, and other suspended materials in the water column (Bruner et al. 1994). Large round gobies (> 50-mm length) feed primarily on zebra mussels less than 20 $\mathrm{mm}$ in length (Jude et al. 1995; French and Jude 2001). Prior to the invasion of round gobies into the Great Lakes, relatively few species there consumed zebra mussels (French 1993). Therefore, toxic substances accumulated in zebra mussels were released to decomposers only after the mussels died. Because zebra mussels are an important component of the round goby diet, the invasion and spread of round gobies created a mechanism for the transfer of toxic substances in zebra mussels to higher trophic levels. This is because round gobies are reported in the diets of game fishes such as walleye, smallmouth bass, and rock bass (Jude et al. 1995). The effects of the invasion of zebra mussels and of round gobies on the movement of toxic substances from benthic organisms to higher trophic levels are a subject of potential public and environmental health concern (Morrison et al. 1998).

In this study, samples were collected from the Raisin, Saginaw, and St. Clair Rivers, where both zebra mussels and round gobies have invaded. Phytoplankton, amphipods, and benthic algae were also collected from the Raisin and St. Clair Rivers for determination of the extent and profile of PCN accumulation in these lower trophic level organisms. PCBs, including coplanar congeners, were also analyzed in the samples for comparison of their trophic transfer with those of PCNs in zebra mussels and round gobies. 2,3,7,8-Tetrachloro-dibenzo$p$-dioxin equivalents (TEQs) of PCNs (PCN-TEQs) and PCBs (PCB-TEQs) were calculated for evaluation of the relative importance of these two class of organochlorine pollutants in the benthic chain of the Great Lakes.

\section{Materials and Methods}

\section{Sampling}

Smallmouth bass, largemouth bass, round gobies, and zebra mussels were collected from various locations within $1 \mathrm{~km}$ of the Raisin River mouth to Lake Erie (Figure 1). Smallmouth bass were collected near the mouth of the Raisin River and below the highway 24 bridge dam. Amphipods, phytoplankton, and benthic algae were collected at one site within $1 \mathrm{~km}$ of the river mouth. Smallmouth bass, round gobies, zebra mussels, phytoplankton, and benthic algae were collected from the St. Clair River at its confluence with the Belle River, at Marine City, and at Algonac (Figure 1). Round gobies and zebra mussels were collected from the Saginaw River. All of the samples were collected during July-November 1998 and 1999 (Table 1). Several hundreds of zebra mussels were collected from their rocky substrates at each location by snorkeling or SCUBA diving. Zebra mussels ranged in size from 3 to $24 \mathrm{~mm}$. Round gobies generally eat zebra mussels ranging in size from 3 to $12 \mathrm{~mm}$ (Jude et al. 1995). Fish were collected by seining or by electroshocking. Amphipods were collected by turning over rocks and using forceps to collect individual organisms. Phytoplankton was collected using a $10-\mu \mathrm{m}$ plankton net. The phytoplankton samples collected using the $10-\mu \mathrm{m}$ net may contain zooplankton and suspended particles. Nevertheless, zooplankton levels are gener-

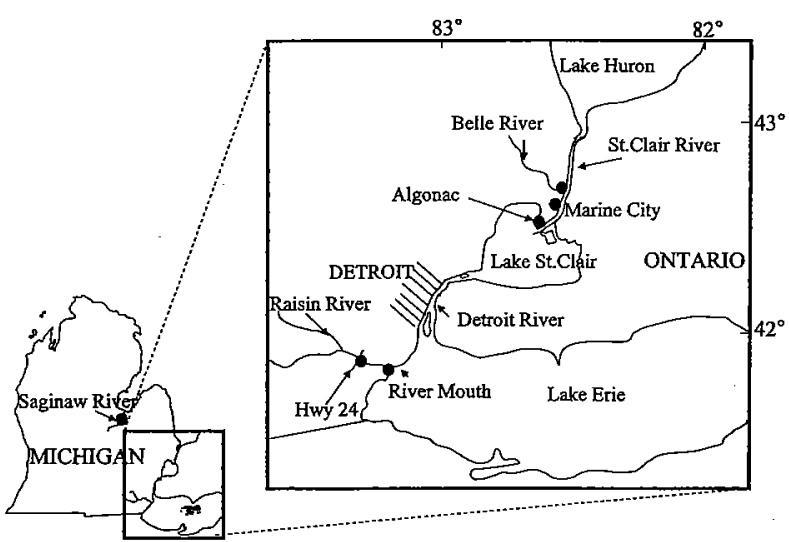

Fig. 1. Map of the lower peninsula of Michigan, showing sampling locations

ally low in these rivers. Benthic algae were collected by scraping hard surfaces with a toothbrush (for nonfilamentous forms), or by handpicking tufts of filamentous algae. Skinless fillets were analyzed for fish except round gobies, for which the whole body was analyzed. Soft tissues were analyzed for zebra mussels. Tissues from several individuals per species were pooled to obtain adequate mass for extraction.

\section{Chemical Analysis}

Chloronaphthalene $(\mathrm{CN})$ and chlorobiphenyl (CB) congeners were analyzed following the method described elsewhere, with some modifications (Kannan et al. 2000). Samples (approximately $20 \mathrm{~g}$ for fish and zebra mussels, 1-4 g for phytoplankton, algae, and amphipods) were homogenized with anhydrous sodium sulfate and extracted in a Soxhlet apparatus for $16 \mathrm{~h}$ using dichloromethane and hexane (400 $\mathrm{mL}, 3: 1$ ). An aliquot of the concentrated extract was used for the determination of fat content by gravimetry. Extracts were then treated with sulfuric acid in a separatory funnel. The solution was concentrated to $2 \mathrm{ml}$ and passed through silica gel packed glass columns. Aliquots of extracts were injected into a gas chromatograph (Perkin Elmer series 600) equipped with a ${ }^{63} \mathrm{Ni}$ electron capture detector (GC-ECD) for the determination of total PCB concentrations.

Identification and quantification of di-, mono-, and non-ortho PCBs and individual PCN congeners were accomplished with a Hewlett Packard 6890 series high-resolution gas chromatograph (HRGC) coupled to a JEOL JMS-700D high-resolution mass spectrometer (HRMS). Di-, mono-, and non-ortho coplanar PCBs and PCN congeners were separated from other ortho-substituted PCBs and pesticides by passing the extracts through a porous Hypercarb graphite carbon column $(100 \times 4.6 \mathrm{~mm}, 7-\mu \mathrm{m}$ particle size; Thermo Hypersil-Keystone, Bellefonte, PA). Details of the fractionation procedure have been described elsewhere (Horii et al. 2001). A Shimadzu liquid chromatograph pump (LC-10AD) was employed to deliver solvents. The first fraction, eluted with $50 \%$ dichloromethane in hexane at a rate of $2.5 \mathrm{ml} / \mathrm{min}(20 \mathrm{ml})$, contained di- and mono-ortho substituted PCBs. The graphite column was then reversed and eluted with toluene (50 ml) to collect non-ortho coplanar PCBs and PCNs. The toluene fraction was further fractionated by passing the extracts through a Cosmosil 5-PYE column (pyrenyl ethyl group; $250 \times 4.6 \mathrm{~mm}, 5-\mu \mathrm{m}$ particle size; Nacalai Co., Osaka, Japan). The first fraction, eluted with $10 \mathrm{ml} \mathrm{10 \%}$ dichloromethane in hexane, contained non-ortho coplanar congeners $77,81,126$, and 169 , and lower CNs. The second and third fractions, eluted with the same solvent mixture, contained more highly chlorinated naphthalenes. The fourth fraction contained the remaining 
Table 1. Concentrations of total PCBs (ng/g, wet wt) and total PCNs (pg/g, wet wt) in aquatic organisms from the Raisin, Saginaw, and St. Clair Rivers, Michigan, USA

\begin{tabular}{|c|c|c|c|c|c|c|c|}
\hline Species & Location & $\begin{array}{l}\text { Length } \\
\text { range (mm) }\end{array}$ & $\begin{array}{l}\text { Weight } \\
\text { range }(\mathrm{g})\end{array}$ & $\begin{array}{l}\text { Date of } \\
\text { collection }\end{array}$ & $\begin{array}{l}\text { Lipid } \\
(\%)\end{array}$ & $\begin{array}{l}\text { Total PCBs } \\
\text { (ng/g) }\end{array}$ & $\begin{array}{l}\text { Total PCNs } \\
(\mathrm{pg} / \mathrm{g})\end{array}$ \\
\hline \multicolumn{8}{|c|}{ Raisin River } \\
\hline Smallmouth bass & Highway 24 & $340-410$ & $620-920$ & 29 Sep 98 & 0.67 & $43.5(6,490)^{\mathrm{a}}$ & $28.2(4,210)$ \\
\hline Smallmouth bass & Highway 24 & $260-310$ & $240-510$ & $29 \operatorname{Sep} 98$ & 0.59 & $45.2(7,660)$ & $15.4(2,610)$ \\
\hline Smallmouth bass & Highway 24 & $170-210$ & $67-135$ & $29 \operatorname{Sep} 98$ & 0.5 & $60.7(12,100)$ & $11.30(2,260)$ \\
\hline Largemouth bass & River mouth to Lake Erie & $345-366$ & $755-990$ & 22 Sep 99 & 0.98 & $1,750(178,000)$ & $223(22,700)$ \\
\hline Round goby & River mouth & $70-96$ & $4.6-13$ & $22 \operatorname{Sep} 99$ & 2.61 & $4,710(181,000)$ & $1,140(43,600)$ \\
\hline Round goby & Port of Monroe & $77-87$ & $7.5-10.2$ & 15 Oct 98 & 2.48 & $2,090(84,300)$ & $336(13,600)$ \\
\hline Round goby & Port of Monroe & $95-109$ & $14: 6-21$ & 15 Oct 98 & 2.18 & $1,990(91,100)$ & $264(12,100)$ \\
\hline Zebra mussel & Port of Monroe & $8-20$ & NA & 15 Oct 98 & 2.41 & $814(33,800)$ & $1,120(46,400)$ \\
\hline Zebra mussel & River mouth & $10-19$ & NA & 6 Aug 99 & $3: 19$ & $2,920(91,400)$ & $1,750(54,800)$ \\
\hline Phytoplankton & River mouth & NA & NA & 13 Oct 99 & 0.99 & $10,200(1,030,000)$ & $12 ; 200 \cdot(1,230,000)$ \\
\hline Amphipod & River mouth & NA & NA & 1 Sep 99 & 1.28 & $4,760(372,000)$ & $1,100(85,900)$ \\
\hline Benthic algae & River mouth & NA & NA & 1 Sep 99 & 0.25 & $194(77,600)$ & $781(313,000)$ \\
\hline \multicolumn{8}{|l|}{ Saginaw River } \\
\hline Round goby & Independence Bridge & $92-105$ & $12.2-18.5$ & 17 Oct 99 & 2.6 & $372(14,300)$ & $189(7,280)$ \\
\hline Round goby & Independence Bridge & $133-144$ & $44-50$ & 17 Oct 99 & 3.24 & $488(15,100)$ & $322(9,950)$ \\
\hline Zebra mussel & Independence Bridge & $4-15$ & NA & 17 Oct 99 & 1.22 & $356(29,200)$ & $362(29,700)$ \\
\hline \multicolumn{8}{|c|}{ St. Clair River } \\
\hline Smallmouth bass & Near Belle River mouth & $174-203$ & $94-132$ & 6 Aug 99 & 0.76 & $55.7(7,330)$ & $32.4(4,270)$ \\
\hline Round goby & Near Belle River mouth & $112-120$ & $78.3-25$ & 30 Sep 98 & 1.55 & $181(11,700)$ & $42.7(2,750)$ \\
\hline Round goby & Marine City & $128-133$ & $34-39$ & 29 Jul 99 & 2.71 & $98.7(3,640)$ & $130(4,810)$ \\
\hline Round goby & Marine City & $77-82$ & $7-8.1$ & $22 \operatorname{Sep} 99$ & 1.35 & $81.3(6,020)$ & $28.7 \cdot(2,130)$ \\
\hline Round goby & Near Belle River mouth & $88-102$ & $9.6-15.3$ & 30 Sep 98 & 2.01 & $146(7,260)$ & $49.9(2,480)$ \\
\hline Zebra mussel & Marine City & $12-24$ & NA & 28 Nov 98 & 0.73 & $31(4,250)$ & $53(7,260)$ \\
\hline Zebra mussel & Marine City & $13-21$ & NA & 6 Aug 99 & 0.74 & $31(4,190)$ & $22.2(3,000)$ \\
\hline Phytoplankton & Algonac & NA & NA & 2 Sep 99 & 0.29 & $768(265,000)$ & $1,370(471,000)$ \\
\hline Benthic algae & Marine City & NA & NA & 29 Jul 99 & 0.18 & $7.3(4,060)$ & $1.96(1,090)$ \\
\hline
\end{tabular}

a Values in parentheses are lipid-normalized concentrations.

PCN congeners. This column fractionation enabled the separation of several PCN congeners, that would otherwise coelute in GC analysis. Each fraction was concentrated and injected into a HRGC interfaced with an HRMS. A Hewlett Packard 6890 series II GC coupled to a JEOL JMS-700D HRMS was used to determine non-ortho PCBs and PCNs. A capillary column coated with DB-17 at a $0.25-\mu \mathrm{m}$ film thickness ( $30 \mathrm{~m} \times 0.25-\mathrm{mm}$ i.d.; J\&W Scientific, Folsom, CA) was used for the separation of individual isomers. The column oven temperature was programmed from $70^{\circ} \mathrm{C}(1 \mathrm{~min})$ to $180^{\circ} \mathrm{C}$ at a rate of $15^{\circ} \mathrm{C} / \mathrm{min}$, then to $270^{\circ} \mathrm{C}$ at $2^{\circ} \mathrm{C} / \mathrm{min}$, with a final hold time of $10 \mathrm{~min}$ for $\mathrm{PCNs}$, and $70^{\circ} \mathrm{C}(1 \mathrm{~min})$ to $200^{\circ} \mathrm{C}$ at a rate of $15^{\circ} \mathrm{C} / \mathrm{min}$, then to $270^{\circ} \mathrm{C}$ at $4^{\circ} \mathrm{C} / \mathrm{min}$, with a final hold time of $15 \mathrm{~min}$ for PCBs. Both of the MS were operated in an electron impact (38-eV energy and $500-\mu \mathrm{A}$ ion current), selected ion monitoring mode, at a resolution $\mathrm{R}$ $>10,000$ (10\% valley). Further details of the instrumental analysis are presented elsewhere (Yamashita et al. 2000a). PCB and PCN congeners are represented by their IUPAC numbers (Wiedmann and Ballschmiter 1993). Total PCBs and PCNs represent the sum of all of the identified tri- to deca-CB and di- to octa-CN congeners, respectively. Data are presented on a wet-and lipid-weight basis, to allow for comparisons, to examine food chain transfer, and for use in risk assessments.

The laboratory has participated in National Institute of Standards and Technology's intercomparison exercises for organochlorines including PCNs. Our results for PCBs and PCNs were within 20\% of the mean value reported for the control material or standards. PCB congener 30 was spiked as a surrogate standard (during Soxhlet extraction) for total PCB analysis. Recoveries of PCB 30 ranged from 78 to $128 \% .{ }^{13} \mathrm{C}$-Labeled PCDD/DF congeners were spiked as internal standards for PCN congener analysis. Recoveries of ${ }^{13} \mathrm{C}$-labeled con-

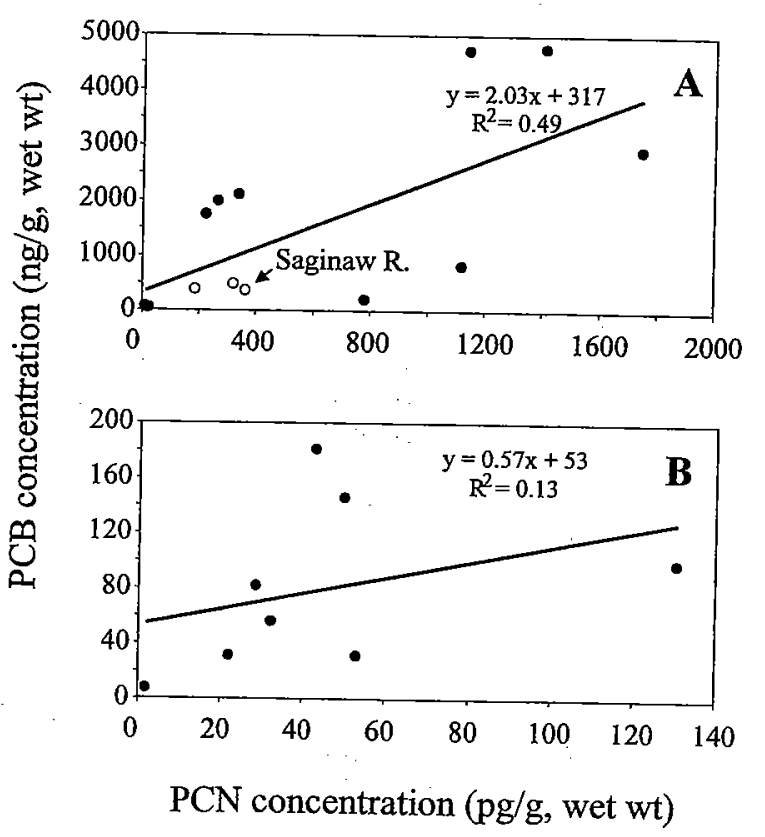

Fig. 2. Relationship between total PCN and total PCB concentrations in benthic organisms collected from the Raisin and Saginaw (A) and St. Clair (B) rivers. Data for phytoplankton from the Raisin River were excluded 


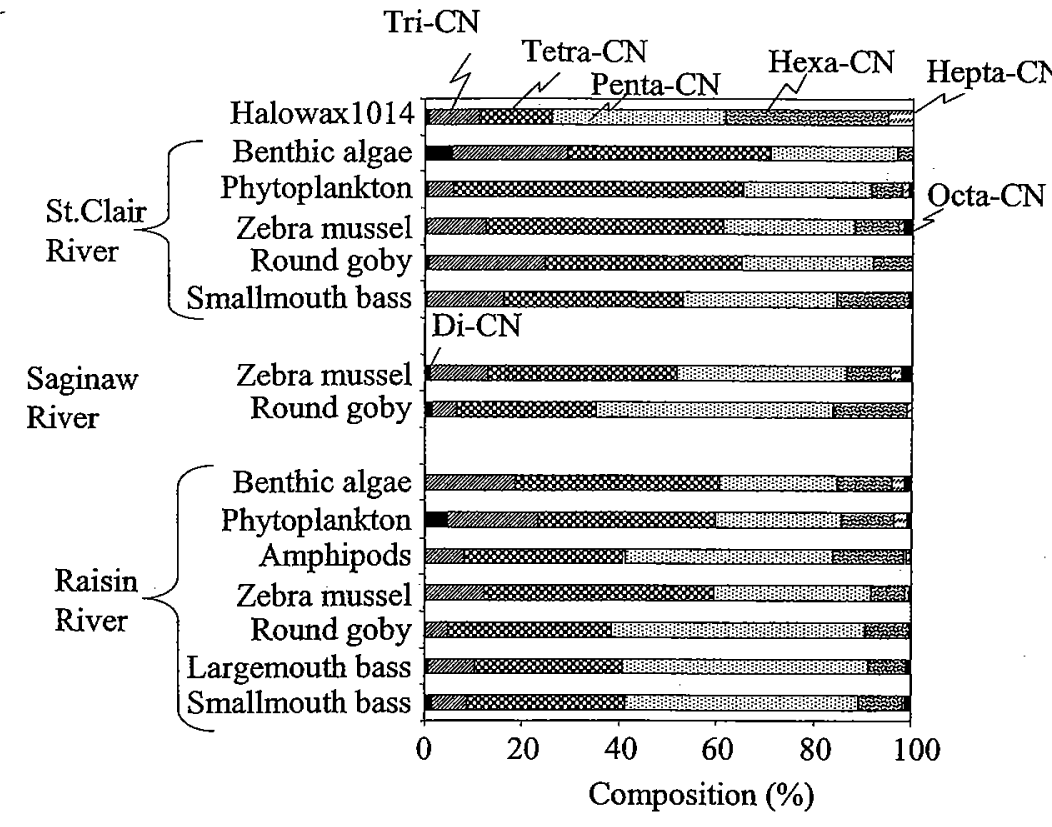

Fig. 3. Mean composition (\%) of PCN homologues in aquatic organisms collected from Michigan waters compared to the $\mathrm{PCN}$ homologue composition of Halowax 1014 geners ranged from 70 to $135 \%$. Reported concentrations were not corrected for the recoveries. Procedural blanks were analyzed for every set of five samples to check for interferences. Calculated concentrations were reported as less than the limit of detection, if either the observed isotope ratio was not within $\pm 20 \%$ of the theoretical ratio or the peak area was not greater than the specified threshold (three times the noise). The detection limits of individual coplanar PCBs and PCN congeners varied from 0.1 to $3 \mathrm{pg} / \mathrm{g}$, wet wt.

\section{Results and Discussion}

\section{Concentrations}

Concentrations of total PCNs in freshwater aquatic organisms analyzed in this study varied from 1.96 to $12,200 \mathrm{pg} / \mathrm{g}$, wet wt (Table 1). The lowest concentration was found in benthic algae collected from the St. Clair River near Marine City and the highest concentration was found in phytoplankton collected from the Raisin River near its mouth to Lake Erie. Concentrations of PCBs also varied widely, from 7.3 to $10,200 \mathrm{ng} / \mathrm{g}$, wet wt. Concentrations of total PCNs in fish were 3 to 4 orders of magnitude lower than total PCB concentrations. High concentrations of PCBs and PCNs found in phytoplankton collected near the Raisin River mouth to Lake Erie suggest the presence of local sources of contamination. Despite their lower trophic status in the food chain, amphipods and benthic algae, also collected at this location, contained anomalously high concentrations of PCBs and PCNs.

Overall, samples collected from the Raisin River contained the greatest concentrations of PCNs and PCBs, followed in decreasing order by samples from the Saginaw and St. Clair Rivers. Concentrations of PCNs in zebra mussels and fish collected from the Saginaw and St. Clair Rivers were lower than those from the Raisin River. For example, lipid-normalized concentrations of PCNs in round gobies collected from the

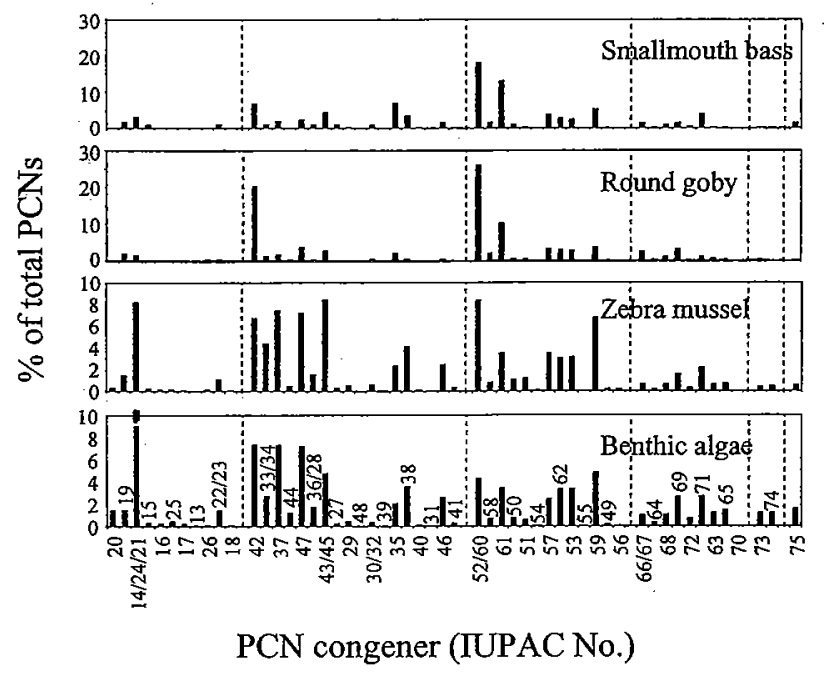

Fig. 4. Profiles of PCN congeners in benthic organisms from the Raisin River, Michigan. Concentrations of individual congeners are reported as the percentage total PCN concentration

Raisin, Saginaw, and St. Clair Rivers were $23,100,8,610$, and $3,050 \mathrm{pg} / \mathrm{g}$, respectively, whereas those in zebra mussels were $50,600,29,700$, and $5,130 \mathrm{pg} / \mathrm{g}$, respectively. The lower River Raisin has been identified by the IJC as an AOC due to contamination by PCBs and heavy metals. Several industrial operations have been suggested as potential sources of PCBs (Collier and Cieniawski 2002). A 1997 sediment-dredging project resulted in the removal of approximately 27,000 cubic yards of PCB-contaminated sediments (maximum concentration $49,000 \mu \mathrm{g} / \mathrm{g}$, dry wt) from the Raisin River near Monroe. Despite this, PCB concentrations in sediments in the remediated area $(>200 \mu \mathrm{g} / \mathrm{g})$ and downstream depositional zones were significantly higher than were upstream concentrations 

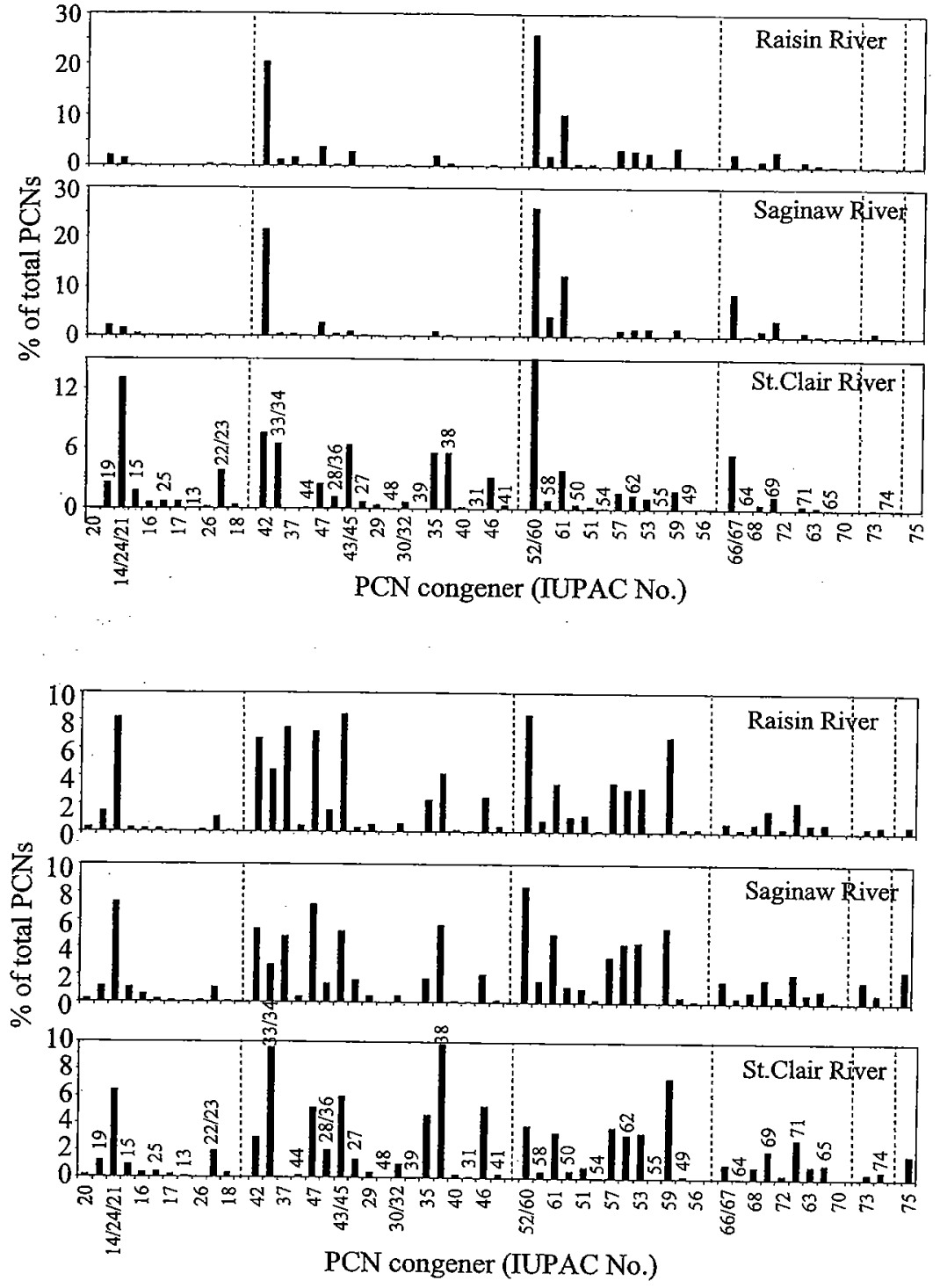

Fig. 5. Contributions (\%) of individual PCN congeners to total PCN concentrations in round gobies collected from the Raisin, Saginaw, and St. Clair Rivers. IUPAC numbers are listed in their gas chromatographic elution order
Fig. 6. Contributions (\%) of individual PCN congeners to total PCN concentrations in zebra mussels collected from the Raisin, Saginaw, and St. Clair Rivers. IUPAC numbers are listed in their gas chromatographic elution order
(Collier and Cieniawski 2002). Moreover, bioaccumulation of PCBs by oligochaete worms (Lumbriculus variegates) was $\sim 100$ times higher in the remediated area than at an upstream reference site (Collier and Cieniawski 2002). Because of the exposure to point sources of pollution in the Raisin River, PCB and/or PCN concentrations in phytoplankton, amphipods, and benthic algae collected at this site were not included in the evaluation of their food chain transfers.

When data for phytoplankton were removed, concentrations of PCNs were significantly correlated with those of total PCBs, in organisms collected from the Raisin River (Figure 2). Nevertheless, PCN concentrations were positively, but weakly, correlated with those of total PCBs in St. Clair River organisms (Figure 2). High concentrations of PCBs in Raisin River organisms imply that these organisms are simultaneously exposed to PCNs present as impurities in technical PCB mixtures (Yamashita et al. 2000b). The mean concentration of PCNs in technical Aroclor mixtures is $39 \mu \mathrm{g} / \mathrm{g}$, which corresponds to $0.0039 \%$ of the total PCB content (Yamashita et al. 2000b). Concentrations of PCNs in aquatic organisms analyzed in this study ranged from 0.01 to $0.4 \%$ (mean: $0.08 \%$ ) of the total PCB concentrations. A greater proportion of PCNs in these aquatic organisms than in technical PCB mixtures suggests that, in addition to technical PCB mixtures, other sources have contributed to the organisms' PCN exposures. Technical PCN mixtures such as Halowaxes, as well as incineration-related activities, could contribute to PCN contamination in the environment.

Concentrations of total PCNs in zebra mussels $(46,400-$ $54,800 \mathrm{pg} / \mathrm{g}$, lipid wt) and round gobies $(12,100-43,600 \mathrm{pg} / \mathrm{g}$, lipid wt) from the Raisin River were in the higher range of the values reported in the literature (Falandysz et al. 1996, 1997; Järnberg et al. 1993, 1997; Corsolini et al. 2002). Concentrations of PCNs found in round gobies were comparable to those $(710-33,000 \mathrm{pg} / \mathrm{g}$, lipid wt) reported for fishes from Michigan waters of the Great Lakes (Kannan et al. 2000). Total PCN concentrations ranging between 540 and $1500 \mathrm{pg} / \mathrm{g}$, lipid wt, were reported in four-horned sculpins from the Gulf of Bothnia (Lundgren et al. 2002). Concentrations of PCNs in muscle tissue of burbot and cod from the Baltic Sea ranged from 2900 


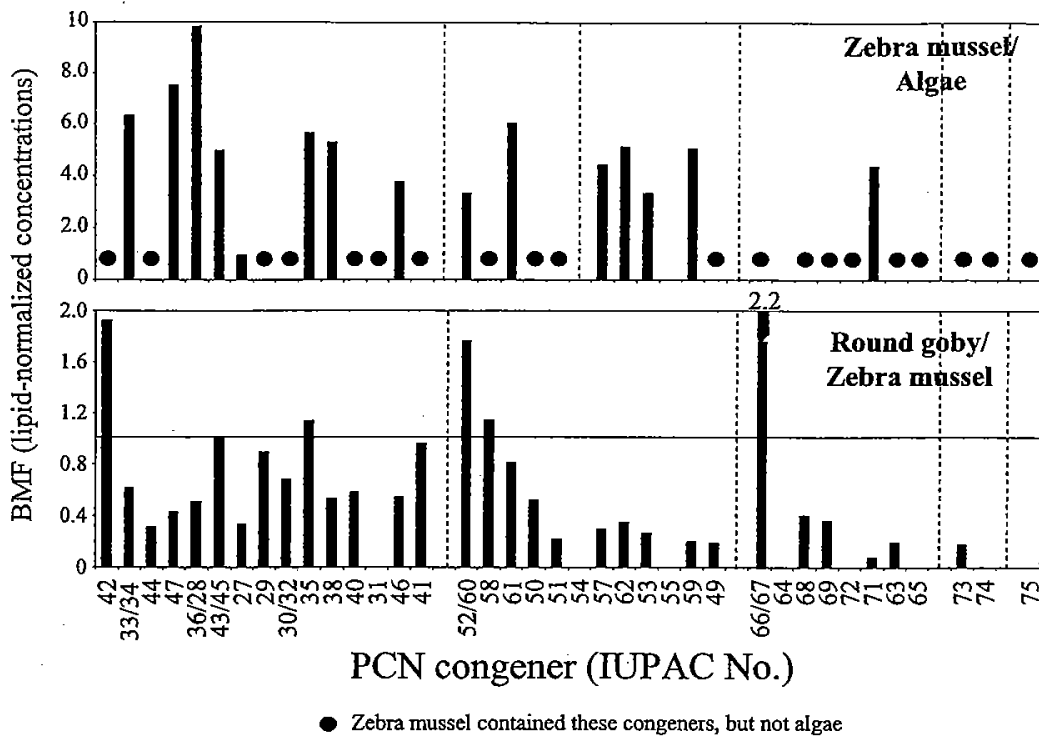

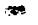

Fig. 7. Biomagnification factors (BMFs: ratio of lipid-normalized concentrations; predator/prey) for PCN congeners between algae and zebra mussels and between zebra mussels and round gobies to $10,000 \mathrm{pg} / \mathrm{g}$, lipid wt (Järnberg et al. 1997). Concentrations of total PCNs in muscle tissue of tuna and swordfish from the Italian coast of the Mediterranean. Sea ranged from 170 to 430 $\mathrm{pg} / \mathrm{g}$, lipid wt (Kannan et al. 2002). Comparison with these results suggests extensive contamination by $\mathrm{PCNs}$ in fish collected from the Raisin River. However, PCN concentrations here were lower than the $504,000 \mathrm{pg} / \mathrm{g}$, lipid wt, found in striped mullet collected near a chlor-alkali plant along the Georgia coast, USA (Kannan et al. 1998).

\section{Homologue Profiles}

Tetra- and penta-CNs were the predominant homologues, accounting for $62-86 \%$ of the total PCN concentrations in the biological samples analyzed in this study (Figure 3). Tetra- and penta-CNs are the major homologues formed during the incineration of solid wastes. The predominance of these homologues has been reported in fly ash originating from solid waste incinerators (Nakano et al. 1993; Takasuga et al. 1994). In Aroclor 1242, a technical PCB mixture, tetra-CNs are the major homologues (Yamashita et al. 2000b). Halowax 1014, a technical PCN mixture, contains penta- and hexa-CNs as the predominant homologues. Some PCN isomers that are prevalent in Halowax 1014 were also the predominant ones found in biological samples analyzed in this study. For instance, PCN congeners $35(1,2,4,8-), 36(1,2,3,5-), 43(1,3,5,8-)$, and 46 $(1,4,5,8-)$ are prevalent in Halowaxes but not in fly ash. The predominance of tetra-CNs in benthic organisms and the presence of PCN isomers 35, 36, 43, and 46 suggest exposure to multiple sources.

In general, the composition of tetra-CNs decreased, while penta-CNs increased, with an increase in trophic level (Figure 4). For instance, the composition of tetra- and of pentaCNs in zebra mussels from the Raisin River was 47 and $32 \%$, respectively, whereas that in smallmouth bass was 32 and $48 \%$, respectively. Similarly, the respective compositions of tetra- and penta-CNs were 49 and $37 \%$ in zebra mussels and 27 and $32 \%$ in smallmouth bass from the St.Clair River. The relative increase in more highly chlorinated homologues with an increase in trophic level may be due to elimination of less highly chlorinated congeners by metabolism and/or due to selective enrichment of more highly chlorinated congeners. Similar to the pattern in this study, tetra- and penta-CN homologues were the predominant congeners in sediments and benthic organisms from the Baltic Sea (Falandysz et al. 1996; Lundgren et al. 2002; Järnberg et al. 1997). Higher trophic organisms such as birds collected from the Great Lakes contained high proportions of hexa-CNs (Kannan et al. 2001a). These results suggest that the less highly chlorinated naphthalene congeners are metabolized in the higher trophic level organisms.

Differences in sources, species-specific accumulation, and metabolism/elimination can contribute to the observed differences in PCN homologue patterns. The profiles of PCN congeners in organisms collected from the St. Clair River were different from the profiles in organisms from the Raisin and Saginaw Rivers. For example, round gobies collected from the St. Clair River contained higher proportions of tri- and tetraCNs than did those collected from the Raisin River (Figure 5). Tri-CN congeners $14 / 24 / 21$ and $22 / 23$ and tetra-CN congeners $33 / 34 / 37,35,38,43 / 45$, and 46 were prominent in round gobies collected from the St. Clair River. However, these congeners were either absent or present only in trace amounts in round gobies collected from the Raisin and Saginaw Rivers. PCN congeners $23,24,33 / 34 / 37,35,43$, and 46 are more abundant in Halowaxes (Falandysz et al. 2000) than in fly ash (Schneider et al. 1998). Congeners 25, 26,30/32, and 39 are less abundant in Halowaxes (Falandysz et al. 2000) but are present in fly ash. These latter congeners were either absent or prsent only at trace levels in St. Clair River organisms. Similarly, zebra mussels collected from the St. Clair River contained those congeners that were abundant in Halowaxes (Figure 6). These results suggest that Halowaxes are the major sources of PCNs in samples collected from the St. Clair River. 
Table 2. Concentrations of PCN-TEQs and PCB-TEQs (pg/g, wet wt) in aquatic organisms collected from the Raisin, Saginaw, and St. Clair Rivers, Michigan, USA $^{\mathrm{a}}$

\begin{tabular}{lllllllc}
\hline & \multicolumn{2}{l}{ Raisin River } & & & & \\
\cline { 2 - 7 } & SMB & LMB & RG & ZM & Amphipod & Phytoplankton & B. algae \\
\hline PCN-TEQs & $0.002(2.2)^{\mathrm{b}}$ & $0.027(0.76)$ & $0.085(1.7)$ & $0.097(4.06)$ & $0.25(1.89)$ & $1.5(6.8)$ & $0.092(14.8)$ \\
PCB-TEQs & $0.089(97.8)$ & $3.51(99.2)$ & $4.79(98.3)$ & $2.29(95.9)$ & $13(98.1)$ & $20.6(93.2)$ & $0.531(85.2)$ \\
Total TEQs & 0.091 & 3.54 & 4.88 & 2.39 & 13.3 & 22.1 & 0.62 \\
\hline
\end{tabular}

Note. SMB — smallmouth bass; LMB-largemouth bass; RG-round goby; ZM-zebra mussel; B. algae-benthic algae. Values have been rounded to three significant digits.

a TEF for PCNs from Blankenship et al. 2000; Villeneuve et al. 2000; Griesy et al. 1997.

${ }^{b}$ Values in parentheses are \% of the total TEQ contribution.

\section{Trophic Transfer}

For the determination of food-chain transfer of PCNs, lipidnormalized concentrations of samples collected from a given location at a given time were used. Lipid normalization was necessary because of the lipophilic nature of the compounds and because of differences in the tissues analyzed for mussels (whole-body soft tissue) and fish (edible muscle tissues for smallmouth bass and whole-body for round gobies). Samples from the Raisin River were not all collected from the same location. Lower-trophic level organisms-phytoplankton, amphipods, and benthic algae - were collected near a point source and, therefore, contained anomalously high concentrations of PCNs and PCBs. Therefore, these lower-trophic level organisms from the Raisin River were excluded from this trophic transfer analysis. However, benthic algae, zebra mussels and round gobies were all collected in 1999 from the St. Clair River near Marine City. This provided an opportunity for us to evaluate the food chain transfer of PCNs and PCBs from algae to round gobies in the St. Clair River. Lipid-normalized concentrations of PCNs in benthic algae, zebra mussel, and round gobies collected in 1999 near Marine City were 1090, 3000, and $3470 \mathrm{pg} / \mathrm{g}$, respectively, suggesting a biomagnification factor (BMF: lipid-normalized concentration in predator/prey) of $\sim 3$ between benthic algae and zebra mussels and round gobies. There was no significant biomagnification of PCNs between zebra mussels and round gobies from the St. Clair River. In fact, concentrations of PCNs in round gobies (mean: $8615 \mathrm{pg} / \mathrm{g}$ ) were $\sim 3$-fold less than those in zebra mussels $(29,700 \mathrm{pg} / \mathrm{g}$, lipid wt) collected from the Saginaw River. Similarly, concentrations of PCNs in round gobies $(12,900$ $\mathrm{pg} / \mathrm{g})$ from the Raisin River near Monroe were $\sim 3$-fold less than those in zebra mussels $(46,400 \mathrm{pg} / \mathrm{g})$ collected from the same site. This may be due to metabolism and elimination of certain less chlorinated PCN congeners and/or enrichment of highly chlorinated congeners in round gobies. However, concentrations of PCNs in smallmouth bass collected in the St. Clair River near the Belle River confluence were 2-fold greater than those in round gobies collected from the same location. Variations in the biomagnification potential of PCNs at different locations may be attributed to differences in the dietary compositions of the species analyzed. In addition to zebra mussels, round gobies feed on aquatic insects and on eggs of other fish species (French and Jude 2001). Therefore, evaluation of biomagnification potential should take into consideration of the dietary composition of the predator species in addition to geographic and biological (e.g., sex, lipid, season) variables. The BMFs of PCNs in zebra mussels are similar to what was reported for cormorants (1.1 to 3.5) from the Baltic Sea (Falandysz et al. 1997). BMFs between PCNs in amphipods (prey species) and the PCN levels in four-horned sculpins ranged from 0.4 to 0.65 (Lundgren et al. 2002).

The biomagnification potential of each $\mathrm{PCN}$ congener varied considerably (Figure 7). On the basis of mean lipid-normalized concentrations of various isomers in benthic algae and zebra mussels from the St. Clair River, BMFs of di-CNs in zebra mussels were less than one, whereas those for hexa-CNs were $\sim 10$. The overall BMF between $\Sigma$ PCNs in algae and $\Sigma$ PCNs in zebra mussels was $\sim 4.9$. The BMFs between PCN congener levels in zebra mussels and the levels in round gobies were less than 1. In general, BMFs increased with an increase in the chlorination level of PCN congeners.

Lipid-normalized concentrations of tetra- to octa- $\mathrm{CN}$ congeners in benthic algae, zebra mussels, and round gobies collected from the St. Clair River near Marine City were used to calculate congener-specific BMFs (lipid-normalized concentrations related as zebra mussel to algae and round goby to zebra mussel). Several PCN congeners that were found in zebra mussels were not found in their diet, algae, at a detection limit of $0.1 \mathrm{pg} / \mathrm{g}$, wet wt (or $56 \mathrm{pg} / \mathrm{g}$ lipid wt) (Figure 7). Although these congeners had been expected to have biomagnified, BMFs were not calculated for these congeners. For those congeners that were found both in zebra mussels and algae, the BMFs varied from 3 to 10 (mean: 4.9). Most of the congeners had high bioaccumulation rates in zebra mussels relative to algae. Zebra mussels, due to their relatively high lipid content, may also concentrate PCNs directly from the water column. Therefore, the calculated BMF for PCNs in zebra mussels is accumulation from both water column and algae/diet. The BMFs of PCN congeners between zebra mussels and round goby were low, varying from $<0.1$ to 2.2 . BMFs of PCN congeners $35,42,43 / 45,52 / 60,58$, and $66 / 67$ were greater than 1. PCN congeners with chlorine substitution at the $2,3,6,7$ positions have been shown to biomagnify considerably (Lundgren et al. 2002). Hexa-CN congeners $66 / 67$ are both substituted at the 2,3,6,7 positions, and these two congeners are the most highly biomagnified ones found in the food chain thus far. Similarly, CN congeners with no vicinal (adjacent) unsubstituted carbon atoms biomagnify considerably (Falandysz et al. 1997). For example, $\mathrm{CN}$ congeners $42,52 / 60,58$, and $66 / 67$, prevalent in zebra mussels, have no vicinal unsubstituted carbons. Although congeners 35 and $43 / 45$ have two vicinal 
Table 2. Continued

\begin{tabular}{llllllll}
\hline Saginaw River & & & \multicolumn{2}{l}{ St Clair River } & & & \\
\cline { 5 - 7 } RG & ZM & & SMB & RG & ZM & Phytoplankton & B. algae \\
\hline $0.084(13.4)$ & $0.043(14.4)$ & & $0.009(2.7)$ & $0.011(2.5)$ & $0.004(22.2)$ & $0.106(4.9)$ & $<0.001$ \\
$0.541(86.6)$ & $0.255(85.6)$ & & $0.319(97.3)$ & $0.424(97.5)$ & $0.014(77.8)$ & $2.05(95.1)$ & $<0.001$ \\
0.63 & 0.298 & 0.33 & 0.44 & 0.018 & 2.16 & $<0.001$ \\
\hline
\end{tabular}

Table 3. Mean concentrations (pg/g wet wt) of dioxin-like PCBs in samples collected from the Raisin, Saginaw, and St. Clair Rivers, Michigan, USA

\begin{tabular}{|c|c|c|c|c|c|c|c|c|c|c|c|c|c|c|}
\hline \multirow[b]{2}{*}{$\begin{array}{l}\text { Congener } \\
\text { No. : }\end{array}$} & \multicolumn{7}{|c|}{ Raisin River } & \multicolumn{2}{|c|}{ Saginaw River } & \multicolumn{5}{|c|}{ St. Clair River } \\
\hline & SMB & LMB & RG & $\mathrm{ZM}$ & Amphipod & $\begin{array}{l}\text { Phyto- } \\
\text { plankton }\end{array}$ & $\begin{array}{l}\text { B. } \\
\text { algae }\end{array}$ & RG & $\mathrm{ZM}$ & SMB & $\mathrm{RG}$ & $\mathrm{ZM}$ & $\begin{array}{l}\text { Phyto- } \\
\text { plankton }\end{array}$ & B. algae \\
\hline \multicolumn{15}{|c|}{ Non-ortho PCBs } \\
\hline 81 & 1.5 & 122 & 153 & 149 & 716 & 806 & 19.6 & 10.5 & 11.8 & 2.2 & 2.2 & $<1$ & 51.8 & $<1$ \\
\hline 77 & 25.1 & 2,530 & 5,040 & 6,040 & 20,300 & 29,900 & 1670 & 215 & 341 & 37.5 & 33.1 & 4.9 & 1,430 & 2.5 \\
\hline 126 & 3.4 & 123 & 176 & 75.3 & 472 & 765 & 18.9 & 20.3 & 8.75 & 12.7 & 16.6 & $<1$ & 79.4 & $<1$ \\
\hline 169 & 6.3 & 2.2 & 3.89 & 0.88 & $<1$ & $<1$ & 0.5 & 1.1 & $<1$ & 4.4 & 4.2 & $<1$ & $<1$ & $<1$ \\
\hline \multicolumn{15}{|c|}{ Mono-ortho PCBs } \\
\hline 123 & 31.8 & 3,900 & 5,360 & 5,270 & 6020 & 10,400 & 368 & 410 & 347 & 88.9 & 201 & $<3$ & 816 & $<3$ \\
\hline 118 & 557 & 92,400 & 80,400 & 40,100 & 126,000 & 172,000 & 5,980 & 8,770 & 5,240 & 1,830 & 3,400 & 52 & 18,700 & 6.8 \\
\hline 114 & 16.1 & 2,650 & 2,165 & 1,080 & 4,890 & 4,670 & 172 & 284 & 160 & 64.8 & 107 & $<3$ & 490 & $<3$ \\
\hline 105 & 210 & 32,800 & 34,500 & 11,400 & 62,300 & 92,000 & 2,500 & 3,000 & 1,740 & 994 & 1,650 & 24.5 & 7,590 & $<3$ \\
\hline 167 & 73.3 & 1,450 & 1,390 & .525 & 2,250 & 5,310 & 123 & 300 & 173 & 209 & 265 & 5.8 & 753 & $<3$ \\
\hline 156 & 93.6 & 2,940 & 2,660 & 1,100 & 4,860 & 12,100 & 327 & 603 & 210 & 367 & 546 & 5.3 & 1,550 & $<3$ \\
\hline 157 & 23.8 & 685 & 570 & 233 & 1,080 & 2,710 & 74.1 & 139 & 65.3 & 90.3 & 123 & $<3$ & 349 & $<3$ \\
\hline 189 & 20.5 & 295 & 270 & 84 & 422 & $<3$ & 35.3 & 50 & 23.3 & 51 & 70.4 & $<3$ & 61.4 & $<3$ \\
\hline \multicolumn{15}{|c|}{ Di-ortho PCBs } \\
\hline 180 & 1200 & 26,200 & 25,200 & 7,190 & 26,400 & 63,600 & 1,880 & 4,140 & 2,250 & 3,400 & 4,890 & 43 & 6,650 & 3.3 \\
\hline 170 & 359 & 7,630 & 6,400 & 2,250 & 8,620 & 21,700 & 782 & 1,250 & 608 & 1,100 & 1,510 & 15 & 2,040 & $<3$ \\
\hline
\end{tabular}

Note: SMB — smallmouth bass; LMB—-largemouth bass; RG—round goby; ZM—zebra mussel; B. algae—benthic algae.

unsubstituted carbon atoms, they biomagnified considerably between zebra mussels and round gobies.

For the comparison of BMFs of PCNs with those of PCBs, lipid-normalized concentrations of total PCBs were compared among benthic algae, zebra mussels, and round goby. Lipidnormalized concentrations of total PCBs in benthic algae, zebra mussels, and round gobies collected in 1999 from the St. Clair River near Marine City were 4060, 4190, and $4830 \mathrm{ng} / \mathrm{g}$, respectively. BMFs for $\mathrm{PCB}$ setween algae and zebra mussels and round gobies were $\sim 1$. No notable magnification of PCBs was observed in round gobies relative to zebra mussels. An earlier study has reported BMFs for PCBs between plankton and zebra mussel vary from 1 to 3 (Ravera 2001; Willman et al. 1999). This is similar to the pattern observed for PCNs. However, round gobies collected from the Raisin River contained PCB concentrations 2- to 3-fold greater than those in zebra mussels. As noted earlier, BMFs appear to vary depending on location, and may be influenced by the dietary composition of predatory species and local sources of contamination. Furthermore, lipid-normalization of concentrations of lipophilic pollutants is suggested to be inappropriate in organisms with low lipid content and in organisms with varying classes of lipids (Bergen et al. 2001).

\section{Toxic Potential}

PCN congeners that elicit dioxin-like activity were found in most of the biota analyzed. These included congeners $52 / 60$ $(1,2,3,5,7-11,2,4,6,7-), \quad 54(1,2,3,6,7-), 57(1,2,4,5,6-), 56$ $(1,2,3,7,8-), 66 / 67(1,2,3,4,6,7-/ 1,2,3,5,6,7-), 68(1,2,3,5,6,8-)$, $69(1,2,3,5,7,8-), 63(1,2,3,4,5,6-), 70(1,2,3,6,7,8-)$, and 73 $(1,2,3,4,5,6,7-)$. TEQs were calculated based on relative potencies derived from H4IIE bioassays (Blankenship et al. 2000; Villeneuve et al. 2000). Concentrations of PCN-TEQs in biota analyzed in this study varied from $<0.001$ to $1.5 \mathrm{pg} / \mathrm{g}$, wet wt (Table 2). Phytoplankton collected from the Raisin River contained the highest PCN-TEQs. For comparison, concentrations of dioxin-like PCBs and their TEQs were also measured and calculated using H4IIE-TEFs (Giesy et al. 1997) (Table 3). TEQs contributed by dioxin-like $\mathrm{PCBs}$ ranged from $<0.001$ to $20.6 \mathrm{pg} / \mathrm{g}$, wet wt. PCBs accounted for 78 to $99 \%$ of the ¿TEQs, whereas PCNs accounted for 1 to $22 \%$ of the TEQs. The highest contribution by PCNs to TEQs was found in zebra mussels collected from the St. Clair River. The range of TEQs contributed by PCNs in benthic organisms analyzed in this study was similar to ranges reported previously (Järnberg et al. 
1993, 1997; Kannan et al. 2000; Corsolini et al. 2002). However, in point source areas, such as the Detroit River and in the vicinity of a chlor-alkali plant in Georgia, PCNs contributed much higher TEQs than did PCBs or PCDDs/Fs (Kannan et al. 1998, 2000, 2001b).

Among dioxin-like PCB congeners analyzed, PCB 126 was the major contributor to TEQs, accounting for $72-99 \%$ of the PCB-TEQs (Table 3). The contribution of each PCN congener to TEQs varied, depending on the species. In general, PCN congeners 66 and 69 were the major contributors to PCNTEQs, accounting for $61-96 \%$ of the PCN-TEQs.

These results suggest that zebra mussels and round gobies can act as conduits for the transfer of PCBs and PCNs from lower- to higher-trophic level organisms. The biomagnification factor for PCNs between algae and zebra mussels was comparable to those for PCBs. In general, $\mathrm{PCNs}$ biomagnified to some extent ( $\sim 3$ fold) between algae and zebra mussels, although no remarkable biomagnification occurred between zebra mussels and round gobies. PCNs contributed up to $22 \%$ of the total TEQs in zebra mussels collected the St. Clair River.

Acknowledgments. We would like to acknowledge the Great Lakes National Program, USEPA, for a grant to conduct a portion of this study. Stephen Hensier assisted in the collection of samples.

\section{References}

Bergen BJ, Nelson WG, Quinn JG, Jayaraman S (2001) Relationships among total lipid, lipid classes, and polychlorinated biphenyl concentrations in two indigeneous populations of ribbed mussels (Geukensia demissa) over an annual cycle. Environ Toxicol Chem 20:575-581

Blankenship A, Kannan K, Villalobos S, Villeneuve DL, Falandysz J, Imagawa T, Jakobsson E, Giesy JP (2000) Relative potencies of individual polychlorinated naphthalenes and Halowax mixtures to induce Ah receptor-mediated responses. Environ Sci Technol 34: 3153-3158

Bruner KA, Fisher SW, Landrum PF (1994) The role of the zebra mussels, Dreissena polymorpha, in contaminant cycling: 1 . The effect of body size and lipid content on the bioconcentration of PCBs and PAHs. J Great Lakes Res 20:725-734

Collier D, Cieniawski S (2002) Post-remediation sediment assessment on the Raisin River, Monroe, Michigan. Paper presented at Sediment Quality Assessment (SQA5) Chicago, IL, October 16-18 sponsored by Aquatic Ecosystem Health and Management Society, Canada

Corsolini S, Kannan K, Imagawa T, Focardi S, Giesy JP (2002) Polychloronaphthalenes and other dioxin-like compounds in Arctic and Antarctic food webs. Environ Sci Technol 36:3490-3496

Falandysz J (1998) Polychlorinated naphthalenes: An environmental update. Environ Pollut 101:77-90

Falandysz J, Strandberg L, Bergqvist P-A, Kulp SE, Strandberg B, Rappe C (1996) Polychlorinated naphthalenes in sediment and biota from the Gdańsk Basin, Baltic Sea. Environ Sci Technol 30:3266-3274

Falandysz J, Strandberg B, Strandberg L, Bergqvist PA, Rappe C (1997) Concentrations and biomagnification of polychlorinated naphthalenes in black cormorants Phalacrocorax carbo sinensis from the Gulf of Gdansk, Baltic Sea. Sci Total Environ 204:97106

Falandysz J, Kawano M, Ueda M, Matsuda M, Kannan K, Giesy JP,
Wakimoto T (2000) Composition of chloronaphthalene congeners in technical chloronaphthalene formulations of the Halowax series. J Environ Sci Health A35:281-298

French III JRP (1993) How well can fishes prey on zebra mussels in eastern North America? Fisheries 18:13-19

French III JRP, Jude DJ (2001) Diets and diet overlap of nonindigenous gobies and small benthic native fishes co-inhabiting the St. Clair River, Michigan. J Great Lakes Res 27:300-311

Giesy JP, Jude DJ, Tillitt DE, Gale RW, Meadows JC, Zajieck JL, Peterman PH, Verbrugge DA, Sanderson JT, Schwartz TR, Tuchman ML (1997) Polychlorinated dibenzo-p-dioxins, dibenzofurans, biphenyls and 2,3,7,8-tetrachlorodibenzo- $p$-dioxin equivalents in fishes from Saginaw Bay, Michigan. Environ Toxicol Chem 16:7:33-724

Harner T, Kylin H, Bidleman TF, Halsall CJ, Strachan WMJ, Barrie LA, Fellin P (1998) Polychlorinated naphthalenes and coplanar polychlorinated biphenyls in Arctic air. Environ Sci Technol 32:3257-3265

Helm PA, Bidleman TF, Stern GA, Koczanski K (2002) Polychlorinated naphthalenes and coplanar polychlorinated biphenyls in beluga whale (Delphinapterus leucas) and ringed seal (Phoca hispida) from the eastern Canadian Arctic. Environ Pollut 119: 69-78

Horii Y, Kaminaka K, Ono K, Okada M, Imagawa T, Yamashita N (2001) Separation of polychlorinated naphthalene isomers and dioxin-like compounds by two dimensional HPLC system with porous graphitic carbon and pyrenyl silica column. Organohalogen Compounds 50:75-78

Järnberg U, Asplund L, de Wit C, Grafström A-K, Haglund P, Jansson B, Lexén K, Strandell M, Olsson M, Jonsson B (1993) Polychlorinated biphenyls and polychlorinated naphthalenes in Swedish sediment and biota: Levels, patterns and time trends. Environ Sci Technol 27:1364-1374

Järnberg U, Asplund L, de Wit C, Egebäck A-L, Wideqvist U, Jakobsson E (1997) Distribution of polychlorinated naphthalene congeners in environmental and source-related samples. Arch Environ Contam Toxicol 32:232-245

Jude DJ, Reider RH, Smith GR (1992) Establishment of Gobiidae in the Great Lakes basin. Can J Fish Aquat Sci 49:416-421

Jude DJ, Janssen J, Crawford G (1995) Ecology, distribution, and impact of the newly introduced round and tubenose gobies on the biota of the St. Clair and Detroit Rivers. In: Munawar M. Edsall T, Leach $J$ (eds) The Lake Huron ecosystem: Ecology, fisheries and management. Ecovision World Monograph Series, Amsterdam, pp 447-460

Kannan K, Imagawa T, Blankenship AL, Giesy JP (1998) Isomerspecific analysis and toxic evaluation of polychlorinated naphthalenes in soil, sediment and biota collected near the site of a former chlor-alkali plant. Environ Sci Technol 32:2507-2514

Kannan K, Yamashita N, Imagawa T, Decoen W, Khim JS, Day RM, Summer CL, Giesy JP (2000) Polychlorinated naphthalenes and polychlorinated biphenyls in fishes from Michigan waters including the Great Lakes. Environ Sci Technol 34:566-572

Kannan K, Hilscherova K, Imagawa T, Yamashita N, Williams LL, Giesy JP (2001a) Polychlorinated naphthalenes, -biphenyls, -dibenzo-p-dioxins, and -dibenzofurans in double crested cormorants and herring gulls from Michigan waters of the Great Lakes. Environ Sci Technol 35:441-447

Kannan K, Kober JL, Kang Y-S, Masunaga S, Nakanishi J, Ostaszewski A, Giesy JP (2001b) Polychlorinated naphthalenes, biphenyls, dibenzo-p-dioxins, and dibenzofurans as well as polycyclic aromatic hydrocarbons and alkylphenols in sediment from the Detroit and Rouge Rivers, Michigan, USA. Environ Toxicol Chem 20:1878-1889

Kannan K, Corsolini S, Imagawa T, Focardi S, Giesy JP (2002) Polychlorinated naphthalenes, -biphenyls, -dibenzo-p-dioxins, 
-dibenzofurans and $p, p^{\prime}-\mathrm{DDE}$ in bluefin tuna, swordfish, cormorants and swallows from Italy. Ambio 31:207-211

Lundgren K, Tysklind M, Ishaq R, Broman D, van Bavel B (2002) Polychlorinated naphthalene levels, distribution and biomagnification in a benthic food chain in the Baltic Sea. Environ Sci Technol 36:5005-5013

Morrison HA, Gobas FAPC, Lazar R, Whittle DM, Haffner GD (1998) Projected changes to the trophodynamics of PCBs in the western Lake Erie ecosystem attributed to the presence of zebra mussels (Dreissena polymorpha). Environ Sci Technol 32:3862-3867

Nakano T, Fujimori K, Takashi Y, Umeda H (1993) Isomer-specific analysis of polychlorinated naphthalenes. Rep Hyogo Pref Inst Environ Sci 25:33-40

Ravera $O$ (2001) Monitoring of the aquatic environment by species accumulator of pollutants: A review. J Limnol 60:63-78

Scheneider M, Stieglitz L, Will R, Zwick G (1998) Formation of polychlorinated naphthalenes in fly ash. Chemosphere 37:20552070

Takasuga T, Inoue T, Ohi E, Ireland P (1994) Development of an all congener specific, HRGC/HRMS analytical method for polychlorinated naphthalenes in environmental samples. Organohalogen Compounds 19:177-182
Villeneuve DL, Khim JS, Kannan K, Falandysz J, Blankenship AL, Giesy JP (2000) Relative potencies of individual polychlorinated naphthalenes to induce dioxin-like responses in fish and mammalian in vitro bioassays. Arch Environ Contam Toxicol 39:273-281

Wiedmann T, Ballschmiter K (1993) Quantification of chlorinated naphthalenes with GC-MS using the molar response of electron impact ionization. Fresenius $J$ Anal Chem 346:800-804

Willman EJ, Manchester-Neesvig JB, Agrell C, Armstrong DE (1999) Influence of ortho-substitution homolog group on polychlorinated biphenyl accumulation factors and fugacity ratios in plankton and zebra mussels (Dreissena polymorpha). Environ Toxicol Chem $18: 1380-1389$

Yamashita N, Kannan K, Imagawa T, Villeneuve DL, Hashimoto S, Miyazaki A; $;$ Giesy JP (2000a) Vertical profile of polychlorinated -dibenzo-p-dioxins, -dibenzofurans, -naphthalenes, -biphenyls, polycyclic aromatic hydrocarbons and alkylphenols in a sediment core from Tokyo Bay, Japan. Environ Sci Technol 34:3560-3567

Yamashita N, Kannan K, Imagawa T, Miyazaki A, Giesy JP (2000b) Concentrations and profiles of polychlorinated naphthalene congeners in eighteen technical polychlorinated biphenyl preparations. Environ Sci Technol 34:4236-4241 